\title{
PRIMEIRO CURSO DE EDUCAÇÃO FÍSICA NA BAHIA - TRAJETÓRIAS E PERSONAGENS
}

\author{
DR. ROBERTO GONDIM PIRES \\ Doutor em Educação - UFBA \\ Departamento de Saúde, Universidade Estadual do Sudoeste \\ da Bahia (Campus de Jequié) (Jequié - Bahia - Brasil) \\ Pesquisador do grupo CORPORHIS \\ E-mail: gondim.roberto@gmail.com
}

DR. CORIOLANO PEREIRA DA ROCHA JUNIOR

Faculdade de Educação, Universidade Federal da Bahia

(Salvador - Bahia - Brasil)

E-mail: coriolanojunior@uol.com.br

\section{DR. FELIPE EDUARDO FERREIRA MARTA \\ Doutor em História (PUC-SP)}

Departamento de Ciências Naturais, Universidade Estadual do

Sudoeste da Bahia (Campus de Vitória da Conquista)

(Vitória da Conquista - Bahia - Brasil)

E-mail: fefmarta@gmail.com

\begin{abstract}
RESUMO
Este texto trata da criação do primeiro curso superior em Educação Física na Bahia e objetiva apresentar seus bastidores, para perceber seus movimentos políticos e acadêmicos. Como metodologia, trabalhamos com os aspectos teórico-metodológicos da História cultural, com foco na história oral, entrevistando pessoas envolvidas com a fundação do Curso. Os dados das fontes orais foram compreendidos como "versões do passado", socialmente situados, articulados com o obtido em documentos e na literatura especializada. Como resultados, identificamos: articulação política externa à Universidade e uso de recursos públicos para fundação do curso; preconceitos institucionais com a Educação Física; coesão no processo de criação e influência da Escola Nacional de Educação Física e Desportos.
\end{abstract}

PALAVRAS-CHAVE: Curso; Educação Física; Bahia; história. 
No Brasil a formação acadêmica civil em nível superior da Educação Física (EF) iniciou-se em 1939, quando foi criada a Escola Nacional de Educação Física e Desportos (ENEFD),' vinculada à Universidade do Brasil (UB). ${ }^{2}$ Sua base legal foi o Decreto Lei I.212 de 17 de abril de 1939 (MELO; ROCHA JUNIOR, 2004). Pelo decreto, a ENEFD teria como funções: formar profissionais de EF; imprimir unidade teórica-prática no ensino; difundir conhecimentos da área e realizar pesquisa, além de capacitar quadros de todo o país, para que estes, ao retornarem aos seus estados de origem, dinamizassem a área pelo Brasil e contribuíssem na criação de outros cursos.

Com a criação de novos cursos em instituições públicas ou privadas, a EF ampliou seus espaços de formação acadêmica. Por isso, analisar a trajetória de constituição, instalação e funcionamento de diferentes cursos nos permite compreender a conformação da área no país (VILELA; ROCHA JUNIOR, 2006).

Neste texto analisamos as tentativas de criação de um curso superior de EF na Bahia, quase todas frustradas, percorrendo uma trajetória que envolveu várias figuras e instituições, até a consolidação do curso da Universidade Católica de Salvador (UCSAL), em 1973, que foi o primeiro da área no estado, reconhecido em 23 de junho de 1977.

A delimitação de nosso interesse pelo curso da UCSAL se deu pelo fato deste ter sido o primeiro do estado, ${ }^{3}$ numa instituição privada, com apoio do poder público. Todavia, reconhecemos a necessidade de apresentarmos dados referentes a outras empreitadas do gênero, que foram muitas e envolveram a ação de professores egressos da ENEFD.

Nosso objetivo foi descrever e analisar dados e fenômenos que balizaram a criação desse curso, buscando compreender as dimensões administrativas, políticas e acadêmicas que lhe foram peculiares, relacionando-as às ações daqueles que foram os atores desta trajetória, os professores fundadores. ${ }^{4}$

Estas intenções justificam-se pela necessária busca de interpretações para eventos como a criação de cursos superiores de EF. Assim, investigar o percurso entre a motivação para a criação, até sua instalação e funcionamento, é em si algo

1. A partir da reforma universitária de 1968, a ENEFD deixa de ser escola padrão e se torna a ainda hoje existente Escola de Educação Física e Desportos da Universidade Federal do Rio de Janeiro.

2. Na atualidade é a Universidade Federal do Rio de Janeiro - UFRJ.

3. Já existiam na Bahia profissionais graduados na ENEFD.

4. Neste aspecto são centrais os dados do livro produzido por Alcyr Ferraro (| 99|), um dos personagens principais da fundação do Curso da UCSAL, que apresenta os elementos básicos para a análise da construção da Educação Física em nível superior na Bahia. 
que faz valer este estudo, permitindo a identificação em seu desenvolvimento de "evidências que permitissem (re)discutir alguns momentos da trajetória da educação física brasileira" (MELO, 1996, p. I).

Neste texto trabalhamos com os aspectos teórico-metodológicos da História cultural, com foco na história oral. Usamos como fontes, os documentos oficiais, a literatura já produzida sobre o tema, as informações de periódicos baianos da época (década de 1970), além de estudos correlatos que tratam de outras Instituições brasileiras. Utilizamos a entrevista não estruturada, realizada com alguns personagens da construção do curso e que por ele passaram como professores ou alunos. Sobre a escolha de quem entrevistar, Alberti (2004, p. 3 I-32) nos mostra que esta deve se guiar

a partir da posição do entrevistado no grupo, do significado de sua experiência. Assim, em primeiro lugar, convém selecionar os entrevistados entre aqueles que participaram, viveram, presenciaram, ou se inteiraram de ocorrências ou situações ligadas ao tema e que possam fornecer depoimentos significativos.

Assim, nosso critério de seleção dos informantes ${ }^{5}$ foi a participação direta desses na criação do referido curso, fundamentalmente os bolsistas que estudaram na ENEFD e que no retorno à Bahia, também tinham como meta criar um curso superior em Educação Física.

Registre-se que são particularmente agudos os obstáculos apresentados ao historiador interessado nesse passado acadêmico. Se a manutenção de importantes arquivos brasileiros é precaríssima, pode-se deduzir a natureza de dificuldades colocadas para o estudo histórico numa localidade onde esta preocupação ainda não é central. Ferraro (1991, p. 13) apresenta um balanço da condição de arquivos e documentos relacionados à Educação Física na Bahia:

... a pobreza de documentos que comprovam os acontecimentos da educação física e do
desporto em nosso Estado [...]. Até mesmo o arquivo inativo que existia na antiga supe-
rintendência de educação física e nas repartiçães subsequentes - como o Departamento
de Educação Física e a Divisão de Educação Física- teve sua documentação destruída ou
extraviada no período em que se instalou no Estádio Otávio Mangabeira. Do exposto,
conclui-se que as décadas de 40 a 80 são absolutamente carentes de documentos que
atestam os fatos desses períodos, com exceção de informes obtidos nos arquivos de jornais.

Nesse sentido, acreditamos que no nosso contexto, a história oral nos abre uma grande possibilidade, a de sistematizar uma possível história da Educação Física na Bahia, pois:

5. Todos os respondentes consentiram com uso das informações obtidas nas entrevistas, na produção deste texto. 
a história faz-se com documentos escritos, sem dúvida. Quando estes existem. Mas pode fazer-se, deve fazer-se sem documentos escritos, quando não existem. Com tudo o que a habilidade do historiador the permite utilizar para fabricar o seu mel, na falta das flores habituais. Logo, com palavras. Signos. Paisagens. Telhas (FEBVRE, 1953, p. 428, apud LE GOFF, 2003, p. 530).

A história oral temática, proposta metodológica do presente estudo, pode ajudar-nos na busca "da "verdade" de quem presenciou um acontecimento ou que pelo menos dele tenha alguma versão" (MEIHY, 1996, p. 4I), pois ela nos oferece interpretações do processo histórico analisado. Por isso, o uso da história oral nos permite centrar atenção nas interpretações "que aqueles que participaram de, ou testemunharam, tal trajetória podem fornecer sobre o assunto. Isso pressupõe que o estudo de tais versões seja relevante para o objeto da pesquisa" (ALBERTI, 2004, p. 30).

Nesse sentido, torna-se necessário reconhecer os limites dessas "versões do passado", bem como da interferência do momento vivido pelo depoente no presente, ao rememorar fatos referentes a um momento de sua vida, por vezes muito distante. Os relatos orais são um documento do presente e por conta disso são aceitáveis... (PORTELLI, 1997).

Dessa maneira, menos do que fazer emergir uma realidade factual, a memória contida nesses relatos nos trazem como valor a subjetividade própria de uma construção de significados em torno dos fatos a que se referem, afinal:

\begin{abstract}
não temos, pois, a certeza do fato, mas apenas a certeza do texto: o que nossas fontes dizem pode não haver sucedido verdadeiramente, mas está contado de modo verdadeiro. Não dispomos de fatos, mas dispomos de textos; e estes, ao seu modo, são também fatos, ou o que o mesmo: dados de algum modo objetivos, que podem ser analisados e estudados por técnicas e procedimentos em alguma medida controláveis, elaborados por disciplinas precisas como a linguística, a narrativa ou a teoria da literatura (PORTELLI, I996, p.64).
\end{abstract}

Vale destacar que as fontes orais mostraram-se fundamentais nesta pesquisa como forma de complementação dos dados, por conta da dificuldade de obtenção de outras fontes documentais. Acreditamos que a possibilidade de ouvir indivíduos que até então não tiveram sua compreensão apreendida, nos proporciou novas representações que por certo abriram outras possibilidades de interpretação do objeto deste estudo. Enfim, consideramos que as fontes orais não só são interessantes, como também imprescindíveis na tentativa de possibilitar uma original investigação da história da Educação Física baiana, ainda pouco discutida e com escassa documentação.

Como organização do texto, optamos por apresentar a seguinte sequência: os projetos de criação de cursos de Educação Física na Bahia; o primeiro curso de 
Educação Física da Bahia; seu currículo e considerações finais. Assim, entendemos ser possível apresentar e discutir o tema em estudo e, por fim, apresentar nossas posições e considerações do assunto.

\section{PROJETOS DE CURSOS DE EDUCAÇÃO FÍSICA NA BAHIA: é doce morrer} no mar....

Em sua obra, Alcyr Ferraro (199|) afirma que a primeira iniciativa para a formação profissional em EF na Bahia deu-se em 1942, na Interventoria de Landulfo Alves de Almeida, ${ }^{6}$ sob inspiração de Isaías Alves de Almeida, Secretário de Educação e Saúde.

Através do Decreto Lei 12.362 de $1^{\circ}$ de julho de 1942, publicado no Diário Oficial em 02 de julho de 1942, o governo estadual baixou os atos necessários à criação e instalação de uma escola superior de EF. Este decreto dava providências para o funcionamento da escola e de uma colônia escola, criando os seguintes cursos:

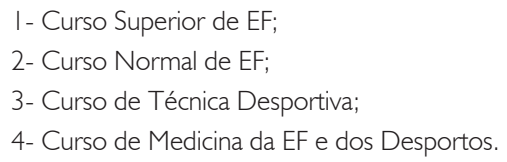

Essa escola funcionaria no Instituto Normal da Bahia (hoje ICEIA), num prédio recém inaugurado, com instalações para as práticas corporais: piscina, ginásio e pista de atletismo. Além disso, todo o material didático necessário ao funcionamento do curso já havia sido adquirido.

Pensando a composição do quadro de professores do projeto da escola, foi enviada para a ENEFD uma segunda turma de alunos, na intenção de capacitá-los para atuarem como docentes. Neste grupo estavam: Calina de Carvalho, Ney Candeias Soares, Hamilton Heróclides Rocha, Lúcia Marques, Lígia Costa, Jacy Moraes, Agenor Santana e Dival Ramos (FERRARO, 1991).

Apesar dos esforços iniciais e das iniciativas tomadas, não se concretizou no governo de Landufo Alves o projeto de uma escola. $\bigcirc$ governo seguinte, do General Pinto Aleixo, com o secretário de Educação e Saúde Álvaro Augusto da Silva, também não deu conta dessa tarefa. Ferraro (199|) afirma que, embora o curso fosse relevante, pela carência de professores da área, esse governo anulou a iniciativa. Assim, todo o material didático adquirido foi distribuído entre o Colégio da Bahia (hoje Colégio Central) e o Instituto Normal da Bahia.

\footnotetext{
6. Entre 1938 e 1942.

7. Instituto Central de Educação Isaías Alves.
} 
Entre 1950 e 1960, 95\% dos professores que atuavam eram considerados leigos, ou credenciados com cursos de curta duração (FERRARO, | 99|). Entretanto, mesmo com essa carência de profissionais, não são conhecidos registros que sinalizem a criação de um curso de EF nesse período.

Em dezembro de 1962, através da lei n 1838, foi criado na Bahia o Departamento de Educação Física, Recreação e Esportes (DEFEBA), que se tornaria o responsável pela organização, fiscalização e difusão dessas áreas na Bahia. Foi através do DEFEBA que mais uma vez se tentou montar um curso superior de EF no estado.

Em 1965, no Governo de Antônio Lomanto Júnior, foi retomado o debate sobre a criação de um curso. O DEFEBA, dirigido por João Alfredo Soares de Quadros, encaminhou por meio do processo 226/65, de 03 de maio de 1965, uma solicitação ao Governador para a criação de uma escola superior de EF.

Através da Portaria $n^{\circ}$ 15, de 13 de setembro de 1965, foi designada uma comissão para elaboração de um plano de trabalho que viabilizasse a implantação da referida escola. O plano foi elaborado e encaminhado para o conselho Estadual de Educação e Cultura que, após exame, baixou a resolução 30/67, criando a escola de EF da Bahia, homologada pelo então governador. Todavia, Ferraro ( 99 | ) afirma que a reforma constitucional de 1967 atingiu a Secretaria de Educação e Cultura, impedindo a implantação da escola. Com isso, o Governador do Estado baixou decreto retirando as providências para sua instalação.

Em 1969, no Governo de Luiz Viana Filho, a partir do Plano Integral de Educação e Cultura, foi feito um diagnóstico do ensino superior na Bahia, que apontou possibilidades e necessidades de cursos superiores para o Estado. Sobre as atividades físico-desportivas, o referido Plano indicava que em 1967 o Estado contava com 354 associações esportivas, congregando na capital 49.088 associados em 5 I unidades esportivas e 300 no interior, com 87.736 membros efetivos.

Esses dados, somados ao diagnóstico das condições infraestruturais (estádio de bom porte, parque aquático e ginásio coberto), apontaram, mais uma vez, a possibilidade de implantação de uma escola superior de EF, por entender que a Bahia possuía amplas perspectivas de incremento esportivo/cultural. A finalidade do curso seria formar professores e pessoal técnico especializado, prevendo o uso do Estádio Otávio Mangabeira, em Salvador, com uma estimativa de custos em torno de $\mathrm{Ncr}^{8}$ । .000.000,00 para obras de adaptação e para a aquisição do material didático e dos equipamentos.

No entanto, mais uma vez, a iniciativa de criação de um curso superior de EF encontrou dificuldades, e desta vez foi na composição do quadro de professores na

8. A moeda vigente na época era o Cruzeiro Novo. 
área das Ciências da Saúde, uma das áreas na formação docente. Assim, de novo, a Bahia teve frustrada sua tentativa de materialização de um curso.

Neste cenário de inexistência de um curso de EF na Bahia, havia dificuldades para o trato com a disciplina no espaço escolar e também para o trabalho com a atividade física e o esporte, forçando a tomada de resoluções para sanar tal quadro. Assim, em 1971, algumas pessoas foram participar de um curso intensivo de Licenciatura de curta duração, na escola Superior de Educação Física de Recife. O objetivo era qualificá-las para que atuassem com a disciplina EF no Estado da Bahia, sobretudo nos futuros Ginásios Polivalentes, criados em 24 cidades do interior. Essa iniciativa se deu através do Programa de Expansão e Melhoria do Ensino (PREMEN), do Ministério de Educação e Cultura, realizado pela Universidade Federal da Bahia, a partir da Faculdade de Educação (FERRARO, 1991).

Várias foram as tentativas para a criação de uma escola de EF e muitas, senão todas, movidas pelos próprios e poucos professores licenciados pela ENEFD. Todavia, por motivos diversos, nenhuma das investidas deu resultado e até o início da década de 1970, a Bahia continuava sem ter seu curso, ficando para trás em relação a vários estados brasileiros, inclusive alguns do nordeste.

Foi só em 1973 que esse cenário sofreu uma mudança e é isso que veremos adiante.

O PRIMEIRO CURSO DE EDUCAÇÃO FÍSICA DA BAHIA: andar com fé eu vou, pois a fé não costuma falhar...

Para Grunnevaldt (1997), a organização de outros cursos de formação de professores no mesmo padrão da ENEFD, tanto em sua organização curricular como nos métodos adotados, foi provavelmente o meio mais eficaz de moldar a EF brasileira.

Souza (1994, p. 75) mostra uma pequena parcela do alcance de tal estratégia, quando diz que em 1953:

por força da lei essa escola estruturou-se nos moldes da ENEFD [...]. Desta forma, a EEFMG (Escola de Educação Física de Minas Gerais) oferecia os mesmos cursos ministrados pela ENEFD, com idêntico elenco de disciplinas e orientações metodológicas semelhantes.

Na Bahia não foi diferente. É importante ressaltar que os idealizadores e articuladores do primeiro curso de EF eram quase todos graduados na ENEFD. Destacam-se os professores Alcyr Ferraro, Neuton Miranda, Fernando Chagas e Georgeochoama (este egresso da Escola de Educação Física do Exército). Todos eles trabalharam no projeto de criação de uma escola superior de EF, que resultou na criação do curso na UCSAL. 
Devemos destacar que, até a concretização do curso da UCSAL, outras instituições foram visitadas para o mesmo intento, como relata o professor Alcyr Ferraro:

[...] então a luta foi muito grande para se criar o Curso de Educação Física. Na Federal não admitiu, nós fomos ao Reitor, através da associação de professores, chamado Lafaiete Ponde na época. Mentalidade assim, tacanha, depois a única solução foi procurar a UCSAL, já que a Federal não tinha condições (depoimento pessoal, 2000). ${ }^{9}$

\section{Este fato é confirmado também pelo professor Georgeochoama:}

[...] o professor Alcyr...envidava esforços junto ao Magnífico reitor da Universidade Federal... para que a escola de Educação Física fosse criada na Universidade Federal, que aliás foi rejeitado de pronto [...], que não era interesse da Universidade Federal naquele momento, criar (depoimento pessoal, 2007). ${ }^{10}$

Em seu depoimento, o professor Georgeochoama relata que, assim que retornou para Bahia, teve a responsabilidade de liderar o processo de criação do primeiro curso superior de EF:

[...] nós aqui nos idos de 1968, 1969, 1970, é... eu fui convidado pelo professor Alcyr Ferraro... para ser presidente da Associação dos professores de Educação Física [risos] então, sendo eleito pelos colegas, assumi a presidência da associação, no sentido de criar a Escola de Educação Física e..., concomitantemente montar cursos de aperfeiçoamento, atualização dos professores leigos (depoimento pessoal, 2007).'

Esses professores, somados a outros, criaram a Associação dos Professores de Educação Física da Bahia (APEFB). ${ }^{2}$ Tal entidade, ao longo de seu funcionamento, transformou o objetivo da criação de uma escola superior de EF em sua meta primordial, notadamente na terceira gestão (biênio 197|/|973), sob a presidência do professor Alcyr Ferraro.

Sobre esse período, afirma Georgeochoama:

[... a acabou a minha gestão, e o professor Alcyr não é? Eu passei para ele e digo olha, já que o Governador é Antônio Carlos Magalhães, é o novo governo, eu não sou afinado com esse governo [...] então eu acho bom você que é uma pessoa mais ligada a esse pessoal [...], assuma a presidência e desenvolva os procedimentos para que agente possa ter a Escola de Educação Física (Depoimento pessoal, 2007). ${ }^{13}$

9. Entrevista pessoal concedida em 16 de março de 1999.

10. Entrevista pessoal concedida em 23 de maio de 2007.

I1. Entrevista pessoal concedida em 23 de maio de 2007.

12. Esta entidade trabalhava na organização da Educação Física e esportes na Bahia, numa tentativa de organizar e sistematizar a área e suas atividades no estado.

13. Entrevista pessoal concedida em 23 de maio de 2007. 
Nesse sentido, a nova gestão da APEFB estabeleceu algumas estratégias, como nos assevera Alcyr Ferraro:

Era fundamental mostrar à comunidade e às autoridades constituídas do Estado, através da imprensa falada, escrita e televisionada, a necessidade da criação da Escola de Educação Física. Os 95\% dos professores não qualificados, trabalhando nos estabelecimentos de ensino público ou particular, eram o atestado de que aquela situação não poderia continuar (FERRARO, 1991, p. 69).

Com esta constatação, a APEFB constituiu uma comissão executiva. Tal comissão tinha o papel de visitar autoridades, entidades e órgãos da imprensa, visando sensibilizá-los para a criação da escola de EF. A comissão fez uma visita ao Reitor Lafaiete Pondé, da Universidade Federal da Bahia e, segundo Ferraro (|99|), o Reitor não mostrou receptividade nem interesse pela causa. Também o Reitor da UCSAL, Monsenhor Eugênio Veiga, foi procurado e argumentou não ter condições para instalação de um curso de EF, por não dispor de instalações específicas.

O professor Alcyr Ferraro ( $199 \mid$ ) comenta que essa comissão executiva da APEFB também visitou a Câmara Municipal de Salvador. A partir desse contato, o vereador lb Matos apresentou um requerimento à mesa diretora solicitando que fosse instalada a escola de EF da Bahia. Na Assembleia Legislativa, o Deputado Newton Macedo Campos encaminhou requerimento pedindo a instalação da escola superior de EF na Capital e em cidades do interior.

A iniciativa da comissão ganhou repercussão nos jornais baianos, que procuravam tratar o assunto, dando destaque ao valor da criação de um curso de EF na Bahia. De certa maneira, a publicação de matérias sobre o assunto acabou sendo uma forma de pressão. Eis alguns exemplos:

- Escola de Educação Física é importante meta para a Bahia (A Tarde, 10 de agosto de |97|); $;^{14}$

- Comissão executiva para a Escola de Educação Física (A Tarde, I4 de agosto de (97|); ${ }^{15}$

- Professores movimentam-se pela Escola de Educação Física. (A Tarde, 20 de agosto de |97|);16

- Educação para o esporte (A Tarde, 24 de agosto de 197I); ${ }^{17}$

- Funcionamento da Escola de Educação Física não demora (A Tarde, 26 de agosto de $197 \mid$ ):;8

14. A Tarde, 10 de agosto de 1971, p. 9.

15. A Tarde, 14 de agosto de 1971, p. 10.

16. A Tarde, 20 de agosto de 1971, p. 12.

17. A Tarde, 24 de agosto de 197I, p.4.

18. A Tarde, 26 de agosto de 1971, p.7. 
- Escola de Educação Física em funcionamento é a meta (A Tarde, 17 de setembro de (97/);19

- Educação Física é valor excepcional de um povo. (A Tarde, 28 de setembro de (97|).20

Nesta conjuntura, onde as ações dos professores e da APEFB não conseguiam resultado, surgiu outra possibilidade. Ferraro ( 199 |) afirma que a Professora Leda Jesuíno ${ }^{21}$ sugeriu que se buscasse a criação de um curso de licenciatura numa unidade de ensino já existente em uma das Universidades baianas, e não a fundação de uma escola própria. Entendia a professora que ao fazer uso de uma estrutura já pronta, a fundação do curso seria mais simples e viável, sem alterar o objetivo básico, formar licenciados em EF.

A UCSAL, para atender a lei 5.540 (da reforma universitária), através do professor Clóvis Veiga, irmão de Dom Eugênio Veiga (Reitor da Instituição), convidou o professor Georgeochoama para implantar as atividades de EF e esporte na Universidade. Esse fato permitiu mais uma iniciativa de constituição de um curso de EF, como nos fala o referido professor:

[... ] eu elaborei um projeto, fiz um arrazoado e no final, no item último eu anotei, portanto, a hipótese de se criar uma Escola de Educação Física, considerando, não é? Mercado, considerando que era uma instituição particular [...] a questão da necessidade de também ter uma escola já que era o único Estado que não tinha uma escola de Educação Física (Depoimento pessoal, 2007).22

É possível que tal sinalização tenha sensibilizado o reitor da UCSAL, Dom Eugênio Veiga, que articulou reuniões com a assessoria jurídica, no sentido de pensar possibilidades de criação de um curso superior de EF, tendo convidado o professor Alcyr Ferraro para se incorporar à Instituição.

Ao que parece esse desenrolar de fatos e acontecimentos se deu dentro de um clima de cooperação, como nos revela o professor Georgeochoama, ao ser questionado sobre disputas no processo:

[...] não, nunca houve. Pelo contrário, era um esforço comum [...] entendeu? todos nós estávamos juntos, unidos, obviamente cada um em cada lugar procurando criar a Escola de Educação Física (depoimento pessoal, 2007). ${ }^{23}$

19. A Tarde, 17 de setembro de 1971, p.12.

20. A Tarde, 28 de setembro de 1971 , p. 12.

21. Diretora da Faculdade de Educação da Universidade Federal da Bahia.

22. Entrevista pessoal concedida em 23 de maio de 2007.

23. Entrevista pessoal concedida em 23 de maio de 2007. 
Já demovidos ${ }^{24}$ da ideia de criação de uma escola superior de EF, mas ainda motivados para a fundação de um curso, os professores Alcyr Ferraro, Neuton Miranda e Fernando Chagas procuraram uma forma de sensibilizar o então governador do Estado, Antônio Carlos Magalhães, quando de uma visita sua ao Colégio Estadual da Bahia (Central).

Os professores incluíram, numa programação festiva do colégio, uma demonstração de ginástica, com aproximadamente 500 alunos, ocupando, segundo Ferraro (|99|), praticamente todo o espaço físico das instalações desportivas e áreas adjacentes. Após a demonstração, a comissão executiva da APEFB e mais três alunos da escola foram solicitar ao governador a instalação de uma escola de EF.

Ferraro (|99|) afirma que eles obtiveram do Governador a seguinte resposta: "escola superior isolada na Capital eu não crio, instalamos Universidades no interior". A comissão não recuou e fez-lhe uma contraproposta, que foi a de firmar convênio com a Universidade Católica do Salvador, para principalmente fazer uso das instalações da Vila Olímpica (propriedade do Estado). A isso, o Governador de pronto respondeu: "topo".

Com a perspectiva da criação de um curso de EF numa instituição privada, a UCSAL, o Estado da Bahia aplicou somas de recursos públicos, tanto em instalações (Vila Olímpica), quanto em material, para viabilizar a materialização daquele que se tornou o primeiro curso na Bahia. Assim, essa posição do Governador atendeu a dificuldade apontada pela UCSAL, ausência de espaços, dando margem à criação do curso.

Em relação a esse fato, o jornal A Tarde, em 29 de junho de 1972, ${ }^{25}$ apresentou a seguinte matéria: "Educação Física tem Escola na Bahia":

Na oportunidade, o Governador Dr. Antônio Carlos Magalhães manifestou a disposição do seu governo em prestigiar a juventude universitária em particular, e a toda mocidade da Bahia, em geral, adiantando que, com este convênio, a juventude terá condições de realizar suas atividades, trazendo assim benefícios não só para o Governo, como para a UCSAL e para toda a comunidade baiana.

A partir de então, com a afirmaç̧ão do convênio entre UCSAL e o estado da Bahia, o grupo de professores viveu meses de expectativa para a aprovação do curso no Conselho Universitário e sua criação efetiva e, ainda, a realização do vestibular. Foi só em 27 de dezembro de 1972, após reunião do Conselho Universitário, que o curso de EF da UCSAL foi aprovado, com o início de seu funcionamento previsto para 1973.

24. A partir da sugestão da Profa. Leda Jesuíno.

25. A Tarde, 29 de junho de 1972, p. 13. 
Para ingresso no curso, o candidato deveria prestar o vestibular para a área Il (Ciências Biológicas). Classificado, o candidato passaria por uma bateria de testes, que eram: exames clínicos; exames de laboratórios e testes biométricos; avaliação da aptidão física, que se consistia de testes de habilidades motoras, teste de Cooper e teste de eficiência natatória.

Como já acontecia antes, a imprensa baiana acompanhava de perto a materialização do primeiro curso de EF. $O$ assunto foi matéria nos jornais da época:

- Aptidão Física vai reprovar candidatos (A Tarde, 16 de fevereiro de 1973); 26

- Mulheres fizeram biométrico com torcida, palmas e vaias (Diário de Noticias, 20 de fevereiro de 1973). ${ }^{27}$

Vemos então que a meta maior, instalação de um curso de EF, foi alcançada e isso, a partir de um convênio entre uma Universidade já existente, que faria uso de sua estrutura acadêmica e o Estado, que entraria basicamente com instalações e equipamentos na esfera esportiva. A fase seguinte seria a viabilização do funcionamento do curso.

Cabe salientar que a efervescência para a criação e subsequente materialização do primeiro curso de EF na Bahia (1973) se deu numa época em o país vivia um contexto político no qual os ventos democráticos estavam reprimidos.

Assim, a perspectiva de formação estava pautada por esse contexto e mesmo pelas possibilidades teóricas da área, que claramente se diferem do entendimento que hoje podemos ter. E foi assim, nesse contexto e nessas condições, que o curso se iniciou.

\section{ENFIM O CURSO: QUEMÉ ATEU E VIU MILAGRES COMO EU...}

Apesar do convênio que permitiu a criação do curso da UCSAL, que previa o uso de espaços e equipamentos, Ferraro ( 1991 ) afirma que em sua implantação não havia nem mesmo sede própria, desenvolvendo suas atividades em várias localidades:

as matérias pedagógicas eram dadas na Faculdade de Educação e no Convento da Lapa, as médicas na Escola de medicina e saúde pública, e as matérias profissionalizantes da Educação Física eram ministradas pelo Departamento de Educação Física da Universidade Católica do Salvador, na Vila Olímpica da Bahia, graças ao convênio entre o Governo do Estado e a UCSAL (p. 79).

26. A Tarde, 16 de fevereiro de 1973, p. 10.

27. Diário de Noticias, 20 de fevereiro de 1973, p. 2. 
A ausência de sede própria e a necessidade de realização de parcerias para garantir o funcionamento inicial do curso também foram fatos observados em outras localidades e instituições, como por exemplo: na Escola Superior de Educação Física de Porto Alegre, conforme apontou Goellner, et al (20 I 0); na Escola de Educação Física do Paraná (SILVA; CAPRARO, 201 I ) e, segundo Vilela e Rocha Junior (2006), o mesmo se deu em Instituições privadas, como a Escola de Educação Física de Volta Redonda.

A coordenação do curso ficou a cargo essencialmente do professor Alcyr Ferraro e de outros professores que tiveram formação na ENEFD. Destacam-se os professores Neuton Miranda e Fernando Chagas (BC).

Alguns professores, também egressos da ENEFD, não aceitaram participar das ações iniciais do curso, caso do professor Manoel Brasil de Freitas. Já Georgeochoama, que acompanhou e atuou em todo o processo, teve sua indicação recusada diretamente pela Diretora da Faculdade de Educação da UCSAL, professora Otávia Veiga.

A coordenação do curso de EF da UCSAL procurou guardar uma identidade com as concepções de Educação, Educação Física e formação profissional difundidas pela ENEFD, mas tal ideário não passou sem que houvesse discordâncias:

[... ocorre que esse currículo aí, essa grade curricular, foi montada de acordo mesmo com a ideia que se tinha de Educação Física aqui na Bahia. Não era propriamente uma ideia que eu comungasse, mas, de qualquer sorte, é... vinha ao encontro primeiro dos professores existentes, compreendeu? (GEORGEOCHOAMA em depoimento pessoal, 2007). ${ }^{28}$

Nesse momento, a formação se dava tendo como referência a resolução de formação profissional 69/69.29 Esta resolução tinha por característica três eixos básicos de disciplinas: I) as técnico-esportivas; 2) as biomédicas e 3) as didático-pedagógicas e de formação geral.

Espalhadas dentro do que se chamou currículo mínimo, estas disciplinas seriam as obrigatórias para qualquer curso no país, podendo daí por diante se incluir outras que fossem consideradas necessárias em cada realidade. O curso deveria ter no mínimo três e no máximo cinco anos, com uma carga horária de 1800 horas/aula, sendo conferido ao aluno o título de Licenciado em Educação Física - Técnico Esportivo.

Essa conformação curricular orientou a composição do quadro docente inicial do curso de EF da UCSAL. Por identidades profissionais e de formação, a grande maioria dos professores da área específica foi composta por egressos da ENEFD, mas também outros motivos podem ter norteado estas escolhas.

Os professores José Coelho e Raimundo Coelho, ambos egressos da ENEFD, com papel de destaque na área, tendo sido diretores do Departamento de EF da

28. Entrevista pessoal concedida em 23 de maio de 2007.

29. Apresentada após a Lei 5.540/68, que tratava da reforma universitária. 
Bahia, desconhecem os motivos de não terem sido convidados para o quadro docente da UCSAL, preferindo atribuir razões abstratas para isso:

[...] não sei porque cargas d'água, nunca teve contato conosco, nem nunca nos procurou... quando Georgeochoama veio com a ideia de modernizar ou modificar o ensino...Raimundo não aceitou [...] eu disse ô George, na verdade eu não quero. E ao mesmo tempo quero. Não quero porque pode haver agitação porque eu sou batista (JOSÉ COELHO, depoimento pessoal, 2000). ${ }^{30}$

Acentua-se que esta situação, qual seja, o mecanismo de escolha dos professores, não foi exclusividade da Bahia, sendo observado também em outros estados do Brasil. Silva e Capraro (20l I) indicam que na composição do quadro docente da primeira escola de Educação Física no Paraná, as questões de origem étnica e afinidades políticas se entrelaçavam com suas respectivas formações técnicas.

O professor Georgeochoama também se considera um fundador do curso de EF da UCSAL e relembra em seu depoimento alguns nomes que poderiam ter participado do processo de construção do referido curso, mas ressalta desconhecer questões pessoais ou políticas:

[...] professor Esturaro que terminou não sendo professor, a nossa ideia também era que fosse o professo José Coelho que era uma grande liderança, que também não veio a ser professor, professor Rivas Queiroz de Souza, Coronel da Polícia Militar que também não veio a ser professor, Josair Estrela Gonçalves não veio a ser professor (depoimento pessoal, 2007).31

Após o êxito da empreitada, possível pelo convênio entre a UCSAL e o governo do Estado, veio à fase de efetivação da implantação.

Nesse momento, esses mesmos nomes que na maioria das vezes atuaram juntos, tiveram participação diferenciada ou mesmo não participaram. Tal fato se deveu a diversos fatores e impactou no modelo de organização do curso, já que em sua instalação acabariam representados os modos de ver a EF nesse momento e as influências carregadas por cada um em sua trajetória.

\section{O CURRÍCULO: PASSO A PASSO, PASSANDO, EU PASSO!}

A estrutura curricular do curso de EF da UCSAL possuía 36 disciplinas. Era perceptível a separação entre as disciplinas para homens e para mulheres, mais

30. Entrevista pessoal concedida em 18 de março de 1999.

31. Entrevista pessoal concedida em 23 de maio de 2007. 
notadamente nos $5^{\circ}$ e $6^{\circ}$ semestres, mas ambos os gêneros eram obrigados a cumprir 36 disciplinas para a conclusão do curso. Das 36 disciplinas do currículo da UCSAL na sua fundação, 05 organizavam seus conteúdos à luz das Ciências Humanas, 06 tratavam do conhecimento pedagógico, 08 se pensavam com base nas Ciências Biológicas e 17 eram de cunho técnico-desportivo. Eram elas:

Quadro I. Disciplinas do Currículo

\begin{tabular}{|c|c|c|c|}
\hline $\begin{array}{l}\text { Ciências Humanas } \\
\text { (formação geral) }\end{array}$ & $\begin{array}{c}\text { Conhecimento } \\
\text { didático- pedagógico }\end{array}$ & Ciências Biológicas & Técnico-desportiva \\
\hline $\begin{array}{l}\text { Filosofia; } \\
\text { Estudos dos } \\
\text { Problemas } \\
\text { Brasileiros; Teologia; } \\
\text { Português E Língua } \\
\text { Instrumental }\end{array}$ & \begin{tabular}{|} 
Prática de Ensino; Me- \\
todologia; Organização \\
da EF e do Desporto; \\
Didática; \\
Estrutura e Funciona- \\
mento do Ensino do \\
$1^{\circ}$ e $2^{\circ}$ graus e \\
Psicologia
\end{tabular} & \begin{tabular}{|c} 
Anatomia; \\
Biologia; \\
Biometria; \\
Fisiologia; \\
Higiene; \\
Cinesiologia; Socorros \\
de Urgência e \\
Fisiologia do Esforço
\end{tabular} & $\begin{array}{c}\text { Atletismo I; Atletismo II; } \\
\text { Ginástica I; Ginástica II; } \\
\text { Ginástica III; Ginástica IV; } \\
\text { Ginástica Olímpica; Ginástica } \\
\text { de Reabilitação; Natação I; } \\
\text { Natação II; Basquetebol; } \\
\text { Voleibol; } \\
\text { Rítmica; } \\
\text { Handebol; Recreação; } \\
\text { Futebol ou Rítmica II; Pesos e } \\
\text { Alteres ou Rítmica III. }\end{array}$ \\
\hline
\end{tabular}

Mesmo que em 1973 a ENEFD já não fosse o "curso padrão", ${ }^{32}$ é notória a influência de seu modelo de formação na escola baiana, existindo uma identidade no que se refere à configuração do quadro de disciplinas. Uma diferença se nota na predominância das disciplinas desportivas no curso da UCSAL, deixando transparecer um reforço da concepção de EF centrada na prática esportiva.

Pouco tempo após o início do funcionamento do curso da UCSAL, começaram a aparecer alguns questionamentos sobre a perspectiva de formação profissional idealizada. O professor Georgeochoama afirma que, já no ano de 1975 , propôs alterações em sua estrutura, inclusive a de acabar com o exame físico, por considerar que esse "era uma bobagem". Esse mesmo professor propôs ainda que se discutisse a questão dos chamados métodos ginásticos, por considerar que eram assuntos ultrapassados e descontextualizados.

Foi só na década de 1980, sob inspiração teórica do professor português Manoel Sérgio e de sua proposição conhecida como Ciência da Motricidade Humana ${ }^{33}$ que foram feitas algumas alterações. Todavia, a juízo de muitos, esta

32. Fato ocorrido após a Reforma Universitária de 1968.

33. Mais detalhes sobre este tema ver em ROCHAJUNIOR, Coriolano P. Organização no campo da Educação Física: considerações sobre o debate. Arquivos em Movimento, Rio de Janeiro, v. I , n.2, p. 69-78, julho/dezembro, 2005. 
não chegou a se constituir numa reformulação curricular. Sobre isso nos relata o professor Georgeochoama:

[... aí sim, foi implantado esse currículo, não na sua concepção original, foi alterado [...] aí já foi feita uma colcha de retalho, entendeu?... porque essa coisa de currículo não basta você elaborar teoricamente [...] se os professores não estão, compreendeu? Envolvidos no processo [...] o currículo é a mentalidade, compreendeu? do professorado, isso que é currículo (Depoimento pessoal, 2007). ${ }^{34}$

Leiro, ${ }^{35}$ que estudou no curso de EF da UCSAL, relata e destaca a participação do movimento estudantil no questionamento da estrutura curricular, relembrando dois personagens dessa história:

Na década de 1980, [...] eu acho que importa registrar o movimento [...] nacional dos estudantes de Educação Física que, na Bahia [...] protagonizou uma página histórica importante, na medida em que realizou aqui em Salvador [... o o seu primeiro Encontro Nacional dos Estudantes de Educação Física, e nesse encontro que vale ressaltar a participação direta de dois personagens, é lógico que não são só esses dois, mas esses dois é o que eu destacaria: o professor, hoje professor Ailton Guimarães e o professor Antônio Carlos, conhecido como TV, que a partir daí inclusive se institui o [...] de forma mais crítica os Diretórios Acadêmicos, não só da Católica, e consequentemente questionou o modo, a organização do trabalho pedagógico na Educação Física na Universidade Católica, portanto eu acho que no início da década de 1980 o movimento estudantil, particularmente o D.A. de Educação Física da Universidade Católica cumpriu um papel questionador e importante na formação profissional (depoimento pessoal, 2006). ${ }^{36}$

Leiro (1999, p. 203-204) destaca que o movimento estudantil teve uma participação ativa no questionamento dos rumos da formação profissional que se iniciava na Bahia, investindo em ações que almejavam outra perspectiva de formação:

nos porões do estádio da Fonte Nova, onde funcionava a ESEF, buscávamos, timidamente, encaminhar as deliberações dos nossos fóruns, como, por exemplo, a luta por Universidade pública, gratuita, laica, e de qualidade que nos fez sonhar, mesmo no caso da existência de repressão política com irradiações pedagógicas, em um dia ter um curso de Educação Física na Universidade Federal da Bahia.

\section{CONSIDERAÇÕES FINAIS}

Ao apresentarmos nossas considerações sobre o processo de fundação do Curso da UCSAL, alguns elementos se destacam por fornecerem importantes dados para uma análise dessa trajetória, envolvendo as questões acadêmicas e políticas.

34. Entrevista pessoal concedida em 23 de maio de 2007.

35. Docente da UFBA e UNEB.

36. Entrevista pessoal concedida em 15 de abril de 2006. 
No plano acadêmico podemos considerar que o Curso da UCSAL procurou seguir um modelo de formação, a da ENEFD, afinal, esta foi a Instituição onde se formaram boa parte das pessoas que passaram a atuar como docentes. Assim, sua estruturação curricular se baseou nos aspectos técnicos e esportivos, além do peso das disciplinas da área biomédica. Por mais que se tenha tentado promover alterações curriculares que abraçassem as novas discussões da Educação Física, podemos considerar que as mudanças feitas não foram de fundo, mantendo assim a dinâmica curricular existente. Além disso, na própria formação dos docentes do Curso, também era notória a influência do "padrão" ENEFD.

No campo político, as articulações montadas foram centrais na viabilização do curso, não apenas na sua formulação, mas também na sua estruturação logística. A "pressão" direta sobre o Governo Estadual e sobre suas lideranças, tentando mostrar a "necessidade" de criação de um Curso Superior de Educação Física na Bahia foi fundamental para a orquestração de um mecanismo que permitisse sua instalação. Um apoio a este cenário de orquestração política foi a coesão de interesses na montagem do Curso, por parte dos personagens participantes desse processo.

Essa coesão no desejo de estruturar um curso, não necessariamente se deu também no campo acadêmico, já que se observaram diferenças quanto à compreensão da área. Ao mesmo tempo, destacamos alguns ranços em relação à Educação Física e sua projeção acadêmica, fato que dificultou e atrasou a fundação de um curso nesta área na Bahia. Também por isso, os articuladores procuraram dar destaque ao "papel" da Educação Física na formação de jovens e crianças, ao papel formativo e moralizante do esporte, alinhando-se assim as perspectivas esportivizantes e de caráter moralizador pensadas para a área, na época de fundação do Curso, a década de setenta.

Com tudo isso, o pessimismo da inteligência nos adverte que a Bahia, consubstanciada pela formação profissional que começava a se realizar, procurou obedecer fielmente às linhas da Política Nacional de Educação Física e Esportes, definida pela lei 6.25I/75, que preconizava que o trabalho da área no Brasil teria como objetivos centrais a melhoria da aptidão física da população, o grande aumento da participação estudantil e popular em práticas desportivas. Todavia o otimismo da vontade nos permite reconhecer, mesmo com todas as críticas que hoje é possível fazer, a importância histórica da constituição do curso de EF da UCSAL.

Foi através desse curso que se iniciou o processo de formação profissional na área na Bahia, permitindo a homens e mulheres que não dispunham de condições de deslocarem-se para outros estados da Federação o realizar e mais, criou a ambiência para criação de outros que se seguiram, com destaque para o da Universidade Federal da Bahia, I 5 anos mais tarde. No final das contas, para a nossa história, este talvez não seja um mau resultado. 
First Course of Physical Education in Bahia - Trajectories and Characters

ABSTRACT: This text deals with the creation of the first university degree in Physical Education in Bahia. This search aims to show the behind scenes and to realize the academic and political movements. Therefore the theoretical and methodological aspects of Cultural History were adopted as methodology, focusing on oral history by mean of interviews with people involved in the foundation of the Course. The data from oral sources were understood as "versions of the past," socially situated and collated with those ones obtained in documents and specialized literature. It has been possible to identify the articulations of foreign policy of the University and the use of public resources for the creation of the graduate course in Physical Education, the institutional biases against Physical Education, the cohesion in the creation of that course and the influence of the National School of Physical Education and Sport in it as the search result. KEYWORDS: Course; Physical Education; Bahia; History.

\section{Primer curso de la Educación Física en Bahia - caminos y personajes}

RESUMEN: Este texto trata de la creación de la licenciatura en Educación Física en Bahía y presentar objetivamente sus escenas y realizar sus movimientos académicos y políticos. La metodología de trabajo con los aspectos teóricos y metodológicos de la historia cultural, centrándose en la historia oral, entrevistando a personas que participaran en la fundación del curso. Los datos de las fuentes orales se entienden por "versiones del pasado," socialmente situados, articulados con la obtenida en documentos y literatura. Como resultado, se identificaron: la política exterior conjunta de la Universidad y el uso de recursos públicos para la fundación del curso; sesgos institucionales a la educación física, la cohesión en la creación y la influencia de la Escuela Nacional de Educación Física y Deportes.

PALABRAS CLAVE: Curso; Educación Física; Bahia; historia.

\section{REFERÊNCIAS:}

ALBERTI, V. Manual de história oral. 2. ed. Rio de Janeiro: Ed. da FGV, 2004.

BAHIA. Secretaria de Educação e Cultura. Plano Integral de Educação e Cultura. Bahia, 1969.

BRASIL. Ministério da Educação. Conselho Federal de Educação. Decreto Lei n ${ }^{\circ}$ 12/2, de 17 de abril de 1939. Rio de Janeiro, 1939.

BRASIL. Congresso Nacional. Lei no 5.540, de 28 de novembro de 1968. Brasília, 1968. . Resolução n 69, de 02 de dezembro 1969. Brasília, 1969.

. Resolução nº 03, de 16 de junho 1987. Diário oficial da União, Brasília, n. 172, 1987.

BRASIL. Congresso Nacional. Lei n 6.251, de 8 de outubro de 1975. Diário Oficial da União, Brasília, 09 de outubro de 1975.

FERRARO, A. N. A Educação Física na Bahia: memórias de um professor. Bahia: Ed. da UFBA, 1991. 
GOELLNER, S. et al. ESEF 70 Anos: o processo de federalização sob o olhar discente. Movimento. Porto Alegre, v. 16, n. esp., p. II-36, 2010.

GRUNENNVALDT, J. T. Escola Nacional de Educação Física e Desporto: o projeto de uma época. 1997. Dissertação (Mestrado em Educação) - Universidade Federal de Sergipe, São Cristóvão, 1997.

LE GOFF, J. História e memória. 5. ed. Campinas: Ed. da Unicamp, 2003.

LEIRO, A. C. R. Educação Física na UFBA: dilemas e utopias. Revista da FACED, Salvador, n. 2, p. 203-220, jun. 1999.

MEIHY, J. C. S. B. Manual de história oral. São Paulo: Loyola, 1996.

MELO, V. A. de. Escola Nacional de Educação Física e Desportos - uma possível história. 1996. 199 f. Dissertação (Mestrado em Educação Física) - Faculdade de Educação Física, Universidade Estadual de Campinas, Campinas, 1996.

MELO, V. A.; ROCHA JUNIOR, C. P. Centro de memória da Escola Nacional de Educação Física e Desportos da Universidade do Brasil. Revista Portuguesa de Ciências do Desporto, Porto, v. 4, p. 357, 2004.

PORTELLI, A. A filosofia e os fatos: narração interpretação e significado nas memórias e nas fontes orais. Tempo, Rio de Janeiro, v. I, n. 2, p. 59-72, 1996.

. O que faz a história oral diferente. Projeto História, São Paulo, n. I 4, p. 25-39, fev. 1997.

SILVA, M. M.; CAPRARO, A. M. O contexto de fundação da Escola de Educação Física e Desportos do Paraná: educando corpos para a vida urbana. Revista Brasileira de Ciências do Esporte, Florianópolis, v. 33, n. 3, p. 623-636, jul./set. 2011.

SOUZA, E. S. Meninos, à marcha! meninas, à sombra: a história do ensino de Educação Física em Belo Horizonte ( I 897- 1994). 1994. 265 f. Tese (Doutorado em Educação) - Faculdade de Educação, Universidade Estadual de Campinas, 1994.

VILELA, S.; ROCHAJUNIOR, C. P. Memórias do curso de Educação Física de Volta Redonda: da criação à regulamentação. Arquivos em Movimento, Rio de Janeiro, v.2, n. I , p. 23-28, jan./jun. 2006.

Recebido em: 6 out. 2012 Aprovado em: 24 maio 2013

Endereço para correspondência:

Coriolano P. da Rocha Junior Rua Alagoinhas - 489/504A - Cond. Mirante do Vale Rio Vermelho - Salvador - Bahia CEP. $41.940-620$ 
